\title{
Mathematical and Finite Element Modeling of Micro-Modification for Marine Gear
}

\author{
Xiongxi Wu, ${ }^{1}$ Qifeng Gao, ${ }^{1}$ and Zesong $\mathrm{Li}^{2}$ \\ ${ }^{1}$ Zhejiang Industry Polytechnic College, Shaoxing 312000, China \\ ${ }^{2}$ Ningbo Institute of Measurement and Testing, Ningbo 315048, China \\ Correspondence should be addressed to Xiongxi Wu; xiongxi_wu@163.com
}

Received 23 June 2015; Revised 21 August 2015; Accepted 2 September 2015

Academic Editor: Hyeong Joon Ahn

Copyright (C) 2015 Xiongxi Wu et al. This is an open access article distributed under the Creative Commons Attribution License, which permits unrestricted use, distribution, and reproduction in any medium, provided the original work is properly cited.

Based on the computer simulation technique, this paper used the professional gear design software MASTA and finite element software ANSYS combined with the method of gear micro-modification to redesign the gear profile and eventually realized the optimization design of gear micro-modification. Then the gear transmission model of one-level reducer was established to simulate and analyze the contact equivalent stress, transmission error, and meshing impact before and after gear modification. By comparing the simulations results it is found that gear micro-modification can lower meshing impact load, reduce the vibration strength, make gear transmission steady, and improve the gear bearing capacity. By comparing the transmission error curves and meshing impact load curves before and after gear micro-modification, this helps to understand the effects of gear micro-modification on the gear transmission and provides basis references for the future redesign of the marine gears with high strength and long service life.

\section{Introduction}

In the gear transmission system, the marine gears generally work under conditions of low speed and heavy load, and the meshing impact loading of gear teeth increases with the increasing of the gear rotation speed and the bearing loads and results in the oversize deformation [1]. Besides, the comprehensive errors are inevitably caused in the process of manufacturing and installation. Because of the existence of the comprehensive errors, the gear meshing impact is strengthened, and thus the service life of marine gear would be shortened, the gear's carrying capacity would be reduced, and the transmission noise would be increased $[2,3]$. Gear micro-modification can be introduced to make the surface pressure distribution of gear tooth uniform as much as possible, lower the teeth's partial load, reduce the meshing impact of gear transmission, and keep the tooth operation smooth [4].

The professional gear design software MASTA has strong design calculation and analysis function, simple operation interface, and excellent gear micro-modification analysis functions. Therefore, this paper made use of gear micro-modification analysis function about MASTA and ANSYS to establish the gear transmission model of one-level marine reducer and analyzed the contact equivalent stress, transmission error, and meshing impact before and after gear modification through the simulation models. According to the setup of gear modification parameters, this paper used the method of gear micro-modification to redesign the gear profile and combined the computer simulation technique.

\section{Gear Micro-Modification}

2.1. Micro-Modification of Gear Tooth Profile. Gear tooth profile micro-modification is to be slightly changing the tooth profile to remove interference part of gear meshing, and the amount and shape of gear modification are determined by three aspects of modification amount, modification length, and modification curves [5]. Figure 1 shows the modification curve of marine gear. In this paper, the method that tooth addendum and tooth root of single tooth are modified at the same time was adopted to have tooth addendum and tooth root modification of meshing gears. 


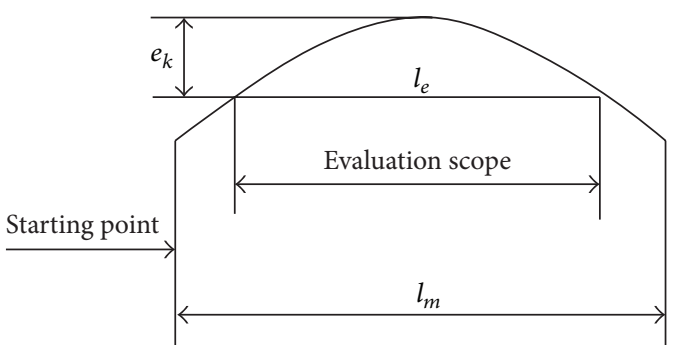

Figure 1: Modification curve of marine gear.

Gear modification path $e$ is described as follows:

$$
e=e_{k}\left(\frac{x}{l}\right)^{b}
$$

where $e_{k}$ is the maximum amount of gear modification, $l$ is the distance from the starting point to the measuring point of the meshing line, $x$ presents the coordinate relative to the meshing point, and $b$ indicates the power exponent, of which the value generally ranges between 1.1 and 2.0 according to [5].

Gear modification distance $l$ along the path is expressed using the following:

$$
l=\frac{\left(L-P_{b}\right)}{2}
$$

where $L$ presents the length of meshing line and $P_{b}$ is the pitch distance.

The maximum amount $e_{k}$ of gear modification appears at the tooth addendum or tooth root, whose value is expressed by

$$
\begin{aligned}
e_{k} & =\delta_{i}+x_{\max }, \\
x_{\max } & =\frac{F_{d}}{\sum K_{v i}},
\end{aligned}
$$

where $\delta_{i}$ represents the interference amount caused by error factors at the position of gear meshing, $x_{\max }$ indicates the greatest total deformation generated by the meshing of involute gear, $F_{d}$ is the meshing force in the normal direction, and $\sum K_{v i}$ presents the composite stiffness of gear meshing.

The meshing stiffness $K_{v i}$ of meshing gear tooth is expressed as follows:

$$
K_{v i}=\frac{\left(K_{z} K_{p v}+K_{c} K_{p v}+K_{z} K_{c}\right)}{K_{z} K_{c} K_{p v}},
$$

where $K_{z}$ presents the meshing stiffness of the driving gear at the meshing position of $i, K_{c}$ presents the meshing stiffness of the driven gear at the meshing position of $i$, and $K_{p v}$ presents the contact stiffness in the gear meshing process.

2.2. Gear Axial Micro-Modification. Gear axial micromodification is mainly determined by two main factors: (a) the location of crowning center in the direction of the
TABLE 1: Gear parameters of one-level reducer.

\begin{tabular}{lcccc}
\hline Parameters & $\begin{array}{c}\text { Teeth } \\
\text { number }\end{array}$ & Modulus & $\begin{array}{c}\text { Pressure } \\
\text { angle }\end{array}$ & Tip circle \\
\hline Pinion & 15 & $2.25 \mathrm{~mm}$ & $17.5^{\circ}$ & $46.8 \mathrm{~mm}$ \\
Main gear & 64 & $2.25 \mathrm{~mm}$ & $17.5^{\circ}$ & $174.4 \mathrm{~mm}$ \\
\hline
\end{tabular}

tooth surface and (b) the crowning amount. In order to solve the problems above, Pedrero and Artés [6] put forward the calculation method of the crowning amount. The crowning amount $C_{c}$ of gear is determined by the effective contact width $b_{\text {cal }}$, tooth width $b$, and the gear meshing skewness $F_{\beta y}$, and if $b_{\text {cal }} / b \leq 1$, then

$$
C_{c}=\left(\frac{2 F_{m} F_{\beta y}}{C_{\gamma} b}\right)^{1 / 2},
$$

where $F_{m}$ presents the circumferential force and $C_{\gamma}$ presents the comprehensive stiffness.

Gear meshing skewness $F_{\beta y}$ is determined by the deviation size of the tooth theoretical position and actual position in the tooth width direction:

$$
F_{\beta y}=F_{\beta x}-Y_{\beta},
$$

where $F_{\beta x}$ presents the skewness at the initial position and $Y_{\beta}$ presents the gear running error at the meshing position, and this paper sets $Y_{\beta}=0.15 F_{\beta x}$ [7], and thus $F_{\beta y}=0.85 F_{\beta x}$. The gear initial skewness mainly consists of two parts, of which the expression is as follows:

$$
F_{\beta x}=f_{s h}-f_{p},
$$

where $f_{s h}$ represents the skewness value caused by bending deformation and torsional deformation, of which the value is given by MASTA software. $f_{p}$ represents the gear meshing skewness value caused by space geometry. $f_{p}$ can be calculated as $2.452 \times 10^{8} \mathrm{~N} / \mathrm{m}$ in accordance with the international ISO 6336-1:2006 standard formula in [8].

The position of gear crowning center distance $b_{c}$ is another important parameter of gear modification. According to the relevant references [9-11], it is shown that the position of gear crowning center distance had better not been chosen at the middle of the tooth width, and the gear crowning center distance $b_{c}$ can be described by twice the length of effective contact width $b_{\text {cal }}$ :

$$
b_{c}=2 b_{\mathrm{cal}}
$$

and if $b_{c} \geq b$, then $b_{c}=b$.

2.3. Gear Transmission Model and Modification Parameters. Gear transmission model of one-level reducer is shown in Figure 2, and in the gear transmission mechanism the pinion is driving the main gear. The gear design parameters of one-level reducer and modification parameters of gear transmission system are shown in Tables 1 and 2, respectively. The design schematic of the pinion studied in this paper is shown in Figure 3, and Table 3 lists the basic material parameters of one-level reducer gear. 
TABLE 2: Gear parameters of one-level reducer via modification parameters.

\begin{tabular}{lcccc}
\hline \multirow{2}{*}{ Gear } & \multicolumn{2}{c}{ Axial modification } & \multicolumn{2}{c}{ Profile modification } \\
& Linear & Crowning & Linear & Crowning \\
\hline Pinion & $0 \mu \mathrm{m}$ & $0 \mu \mathrm{m}$ & $0 \mu \mathrm{m}$ & $0 \mu \mathrm{m}$ \\
Main gear & $10 \mu \mathrm{m}$ & $4 \mu \mathrm{m}$ & $0 \mu \mathrm{m}$ & $12 \mu \mathrm{m}$ \\
\hline
\end{tabular}

TABLE 3: Material parameters of one-level reducer gear.

\begin{tabular}{lccc}
\hline Material & Elasticity modulus & Density & Yield strength \\
\hline $18 \mathrm{CrNiMo}$ & $206 \mathrm{GPa}$ & $7800 \mathrm{~kg} / \mathrm{m}^{3}$ & $850 \mathrm{MPa}$ \\
\hline
\end{tabular}

\section{Simulation Results and Analysis of Gear Micro-Modification}

Based on the gear parameters of one-level reducer in Table 1, the ANSYS software was used to establish the model of onelevel reducer. According to the gear modification parameters designed in Table 2 the transmission model of onelevel reducer was used to obtain the effective stress via micro-modification. Figure 4 shows the static effective stress comparison of the rated conditions (a) and (c) before gear modification and the limit load conditions (b) and (d) after gear modification based on the ANSYS software. It is found from Figure 4(b) that the maximum equivalent stress after gear modification was $403 \mathrm{MPa}$ on the rated conditions, and according to Figure 4(d) the maximum equivalent stress via gear modification was $625 \mathrm{MPa}$ on the limit load conditions. Figure 4(a) shows the maximum equivalent stress before gear modification was $408 \mathrm{MPa}$ on the rated conditions and $643 \mathrm{MPa}$ on the limit load conditions, which do not still exceed the yield strength of the gear material. This is mainly because the contact area after gear modification was reduced, and the maximum equivalent stress of the contact area increased $[12,13]$. Through the comparison of the maximum contact stress, it is found that the maximum contact stress of the pinion before micro-modification was about $408 \mathrm{MPa}$, and the maximum static effective stress after micromodification was about $403 \mathrm{MPa}$; thus the static effective stress of the pinion via gear modification decreased. This indicates that the gear via micro-modification can reduce the tooth surface maximum contact stress of the pinion.

Figure 5 shows the distribution of dynamic effective stress based on ANSYS LS-DYNA and loading force applied to main gear per unit length based on MASTA before/after gear modification. By comparing the gear meshing loading force before and after the micro-modification it is seen that after gear micro-modification the gear meshing impact makes a smooth transition, and the gear meshing loading force along the gear width is diminishing from middle to both sides shown in Figure 5(b). The simulation results show that maximum loading force per unit length before gear micromodification is $670497 \mathrm{~N} / \mathrm{m}$, and the maximum loading force per unit length after gear micro-modification is $655692 \mathrm{~N} / \mathrm{m}$. Additionally, the maximum dynamic effective stress values

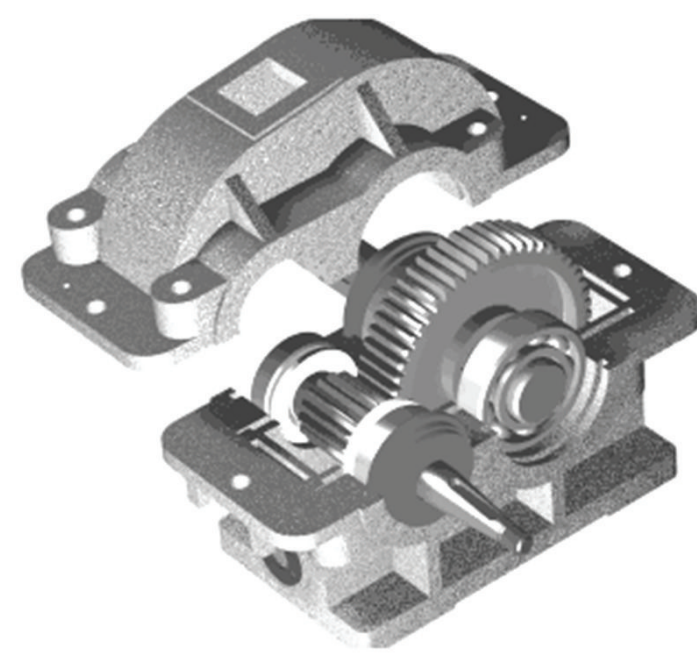

FIGURE 2: Gear transmission model of one-level reducer.
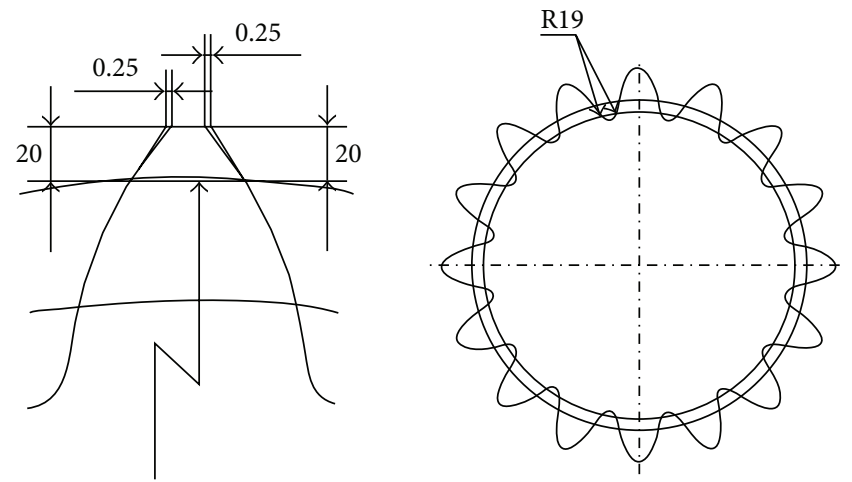

FIGURE 3: Design schematic diagram of the pinion.

before/after gear modification are 289.9 MPa and 225.4 MPa. It is suggested from the analyses above that gear modification can expand the meshing region of tooth width, thus greatly improving multiple mutations of loading force in the process of gear meshing and increasing the bearing capacity of gear teeth.

Figure 6 shows the comparison of contact press computed by MASTA software before and after gear modification, where it is found that the maximum contact stress values computed by MASTA before/after gear modification are $3031 \mathrm{MPa}$ and $2988 \mathrm{MPa}$, respectively. Thus the contact pressure via gear modification was reduced in rated working conditions.

The transmission error curves of the main gears before and after gear modification are shown in Figure 7, in which it can be seen that the maximum transmission error value of transmission error in the gear meshing process before micromodification is about $45.6 \mu \mathrm{m}$, and the minimum value is about $33.7 \mu \mathrm{m}$; after micro-modification the maximum value of transmission error is about $45.8 \mu \mathrm{m}$, and the minimum value is about $39.3 \mu \mathrm{m}$. At the same time, after micromodification the transmission error curve became more and more gentle. This indicates that the gear after micromodification can lower the fluctuation of the transmission 

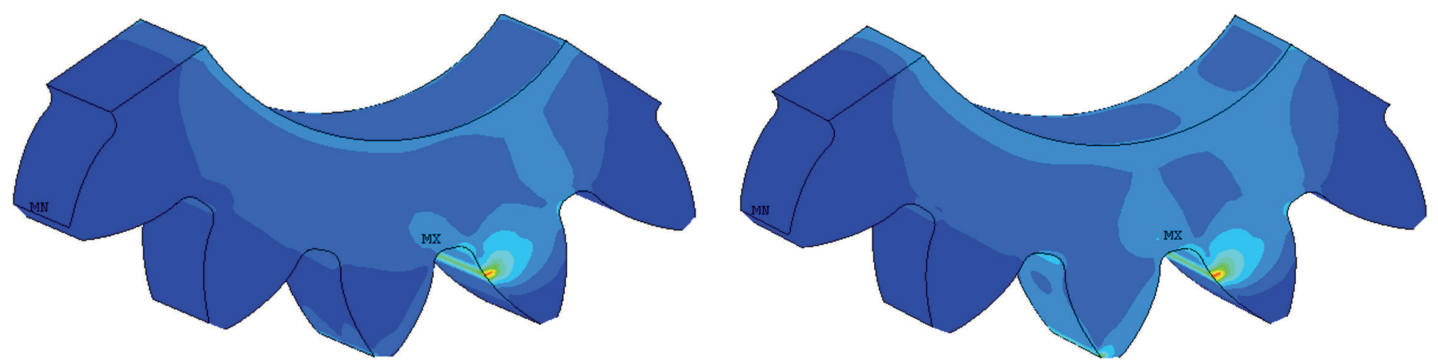

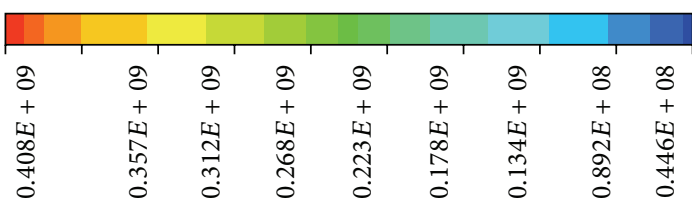

(a)

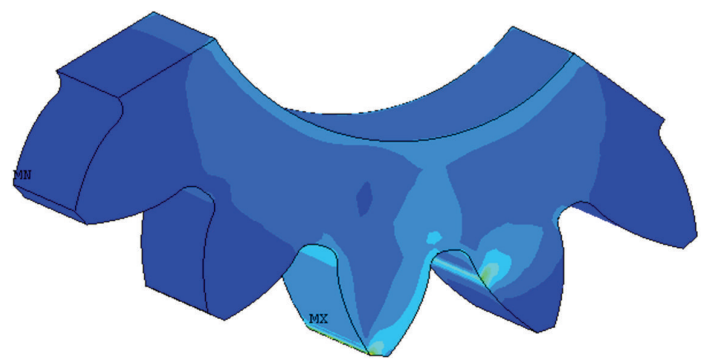

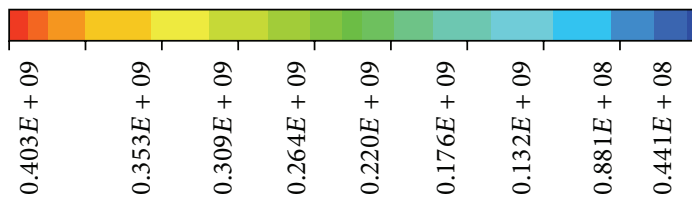

(c)

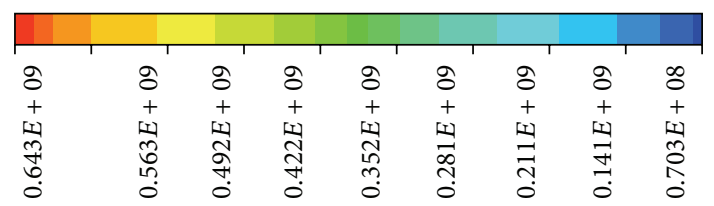

(b)
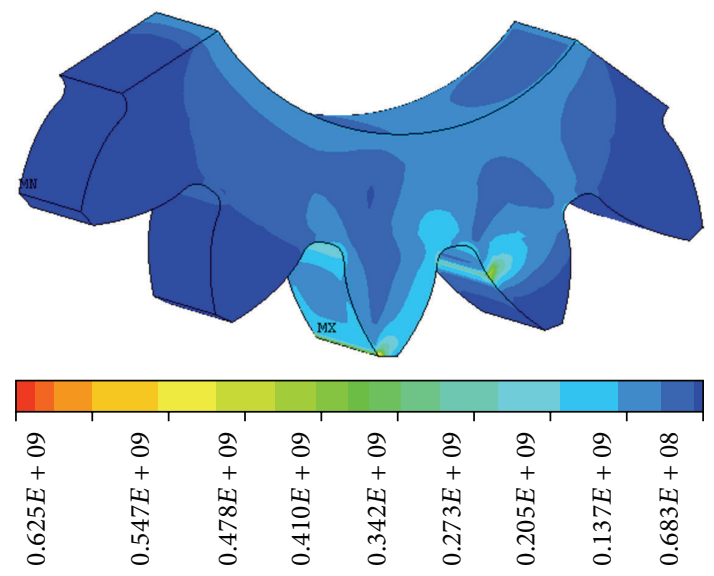

(d)

FIGURE 4: Static effective stress comparison of the rated conditions (a) and (c) before gear modification and the limit load conditions (b) and (d) after gear modification based on ANSYS.

error and make the meshing impact curve more uniform. Gear transmission error curve is one of the most important factors related to dynamic performances of gear transmission system. Figure 7 illustrates that the gear micro-modification can improve the gears' dynamic performances and make the gear transmission system more stable.

Comparison results of the maximum equivalent stress history after and before gear modification on the rated conditions are seen in Figure 8. Through the comparison results of stress history it is found that the maximum equivalent stress history curve before gear modification has three peak mutations near the position of mating teeth coming out of contact. It is illustrated in Figure 8 that the gear before micromodification is easily subject to larger meshing impact in gear meshing process, and the stress concentration at the position of tooth top before mirco-modification is more serious than that after gear modification.

\section{Conclusions}

According to the setup of gear modification parameters, this paper used the method of gear micro-modification to redesign the gear profile and combined the computer simulation technique to establish the gear transmission model of one-level reducer. The conclusions are as follows:

(1) Gear modification can expand the meshing region of tooth width, thus greatly improving multiple mutations of loading force in the process of gear meshing and increasing the bearing capacity of gear teeth.

(2) Compared with the gear after micro-modification, the gear before micro-modification is easily subject to larger meshing impact in gear meshing process, and the sudden change of equivalent stress at the position of tooth top is more serious.

(3) By comparing the transmission error curve and meshing impact load curves before and after gear micro-modification, this helps to understand the effects of gear micro-modification on the gear transmission and provides basis references for the future redesign of the marine gears with high strength and long service life.

Only considering the tooth profile and tooth surface micro-modification of single gear, this paper lacked 

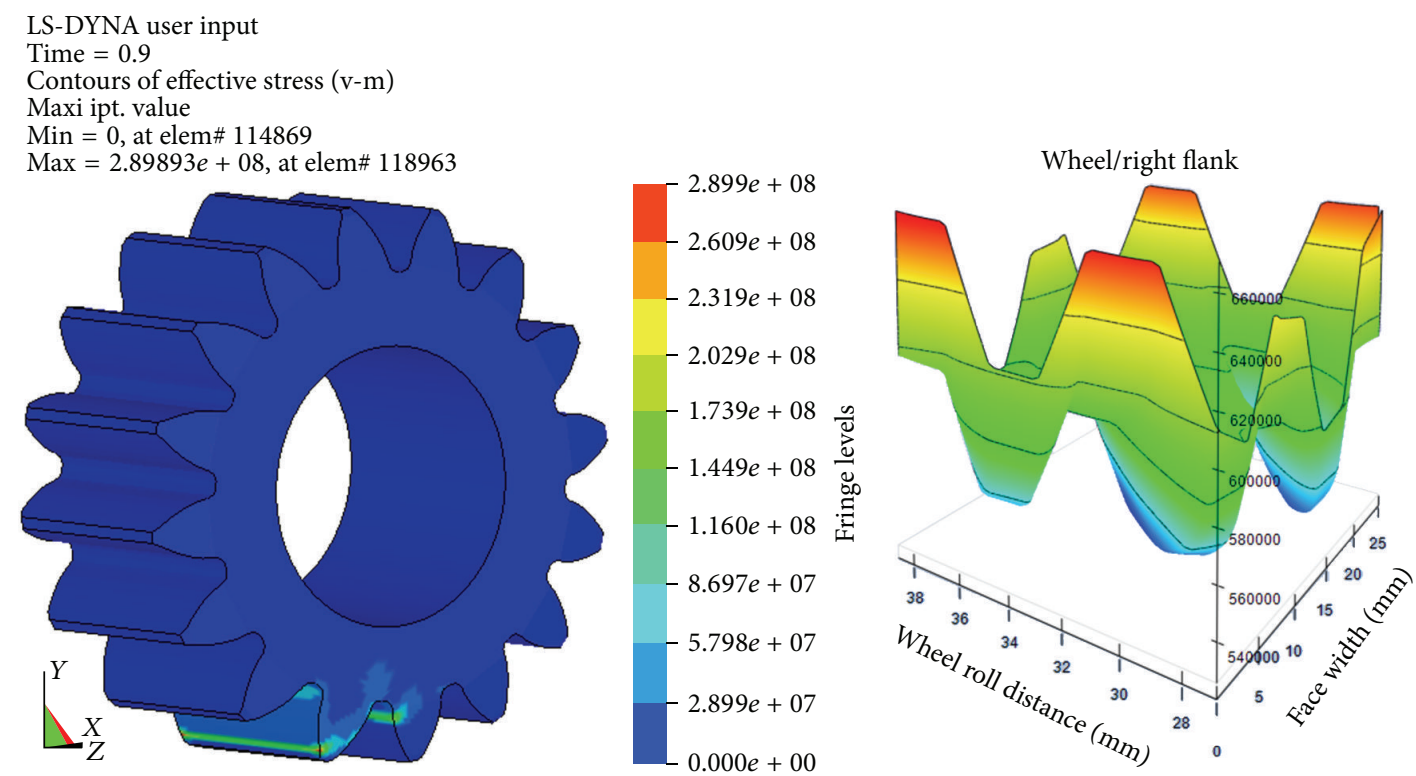

Force per unit length $(\mathrm{N} / \mathrm{m})$
口 525496
$\square 612496$
554496
641496
ㅁ 583496
670497

(a) Before gear modification
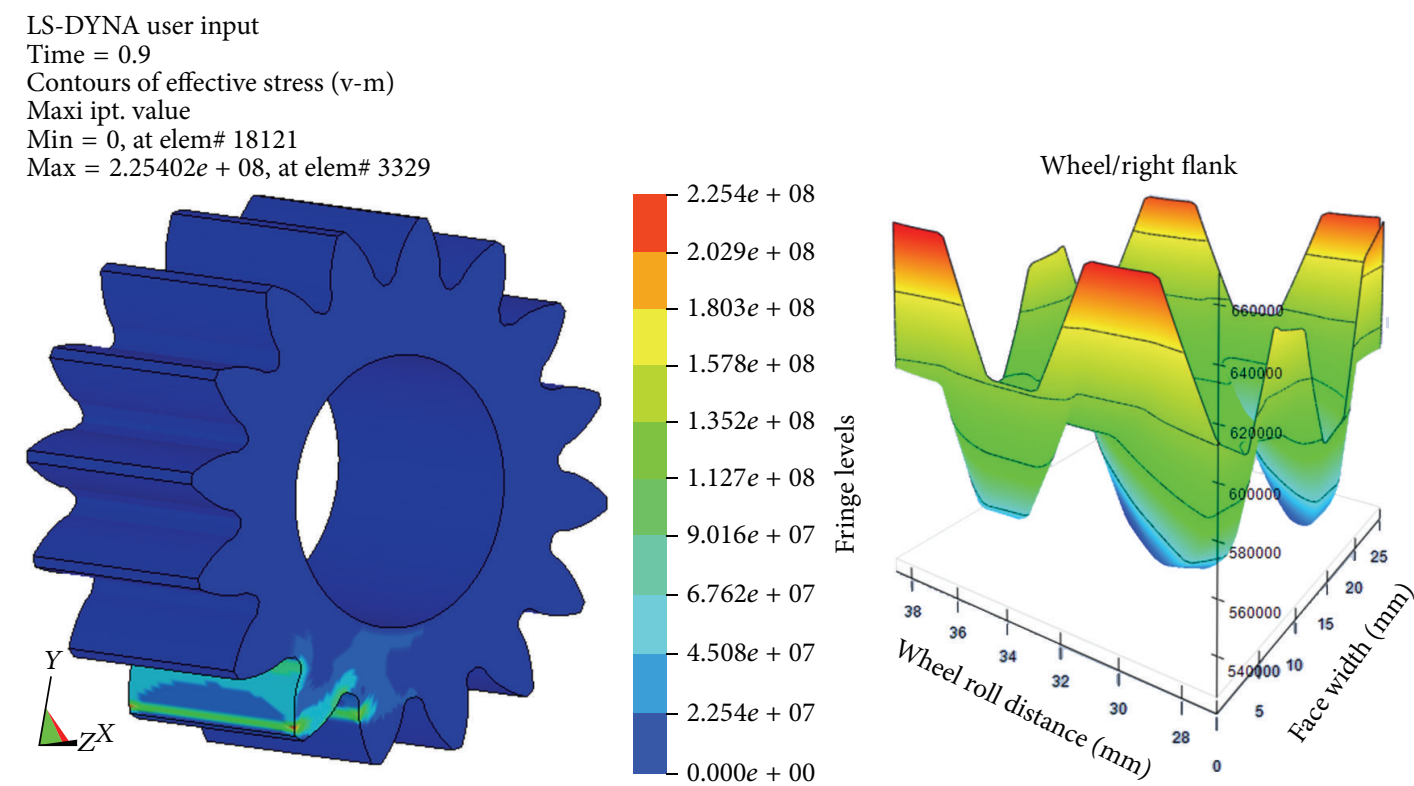

Force per unit length $(\mathrm{N} / \mathrm{m})$
๑ 513897
ㅁ 598974
ㅁ 542256
ㅁ 627333
570615
ロ 655692

(b) After gear modification

FIGURE 5: Distribution of dynamic effective stress based on ANSYS LS-DYNA and loading force applied to main gear per unit length based on MASTA before and after gear modification. 


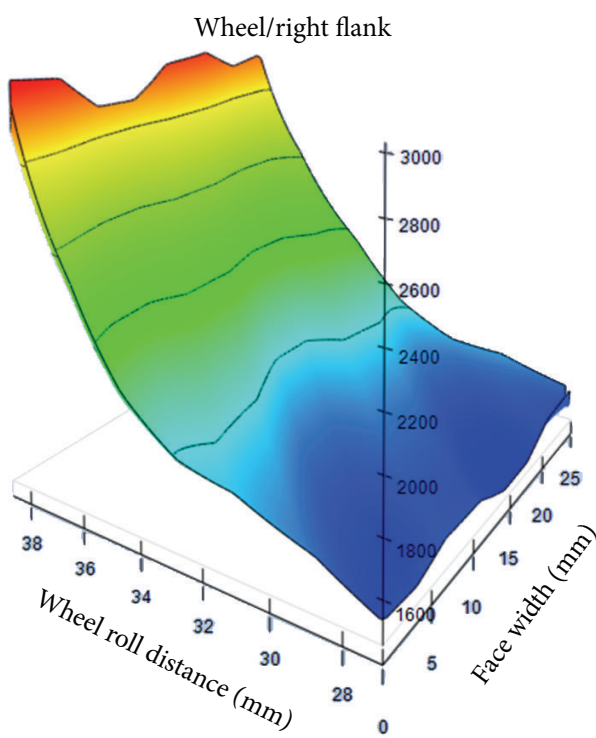

Max contact pressure (MPa)
$\square 1453$
$\square 2400$
1769
$\square 2716$
$\square 3031$

(a) Before gear modification

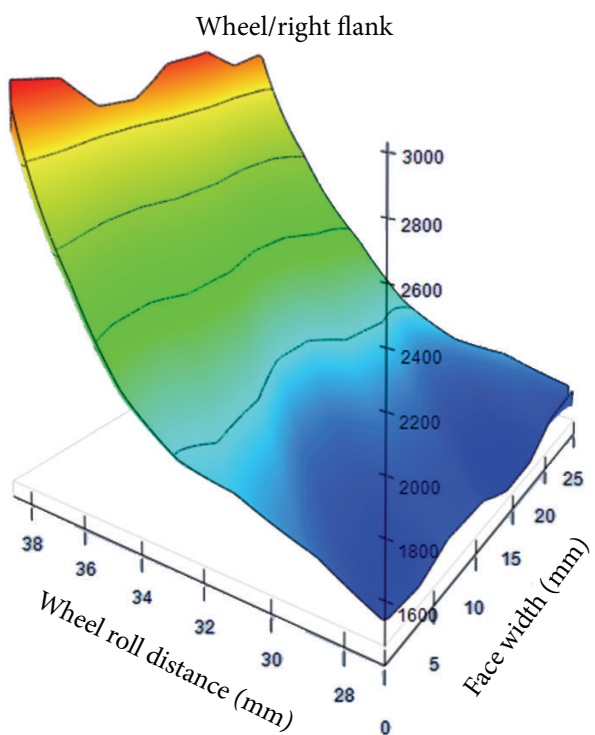

Max contact pressure ( $\mathrm{MPa})$
1437
$\square 2373$
$\square 1750$
ㅁ 2685
$\square 2062$
$\square 2998$

(b) After gear modification

FIGURE 6: Comparison of effective stress computed by MASTA software before and after gear modification.

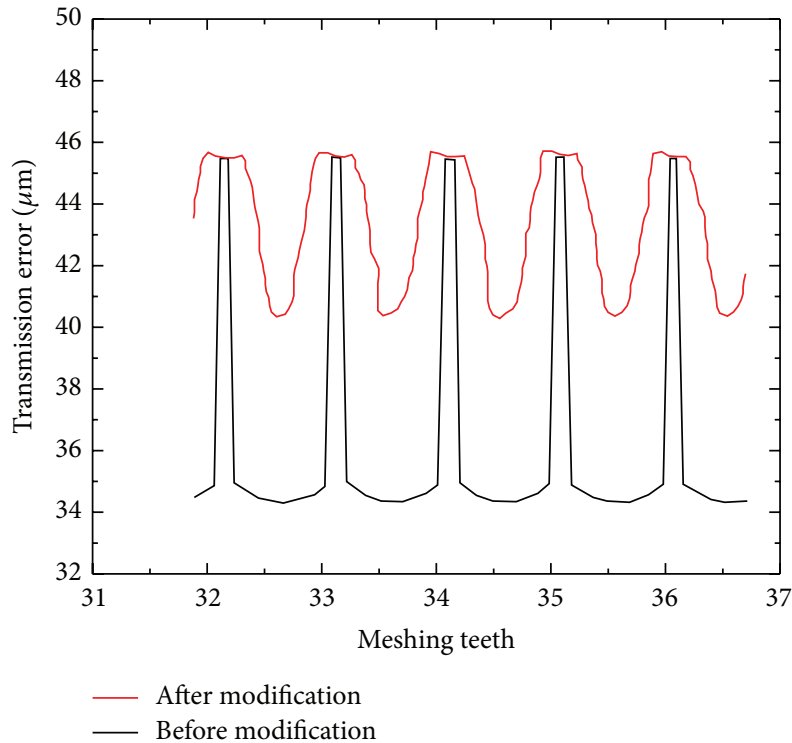

FIGURE 7: Transmission error curve of main gear before and after gear modification based on MASTA.

experimental verification but provides certain reference for redesign of marine gears with high strength, long service life, and smooth transmission.

\section{Conflict of Interests}

The authors declare that there is no conflict of interests regarding the publication of this paper.

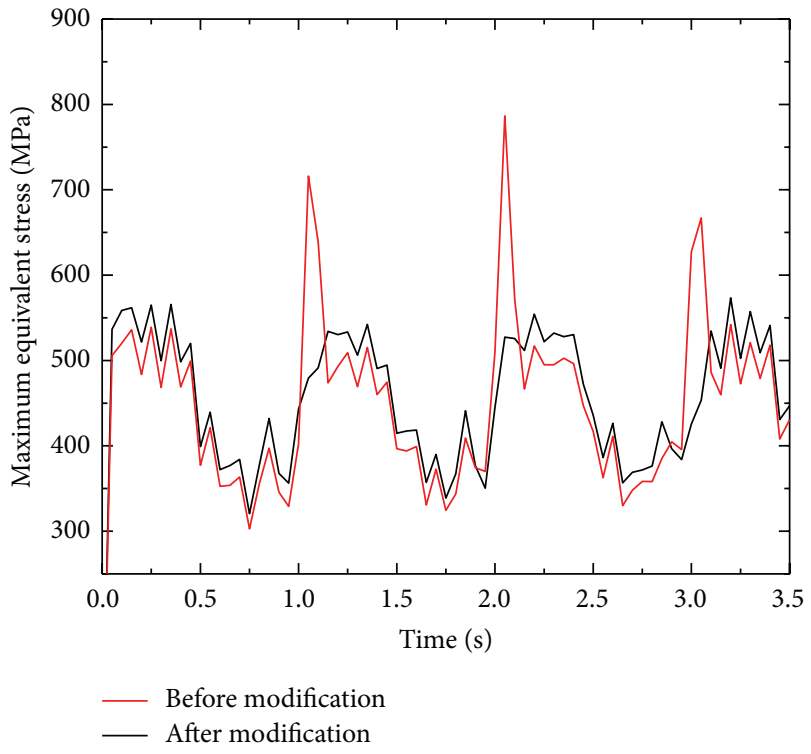

FIGURE 8: Maximum equivalent stress history after and before gear modification on the rated conditions based on ANSYS LS-DYNA.

\section{Acknowledgments}

The authors would like to thank the Project of Zhejiang Department of Science and Technology (Key Program, no. 2012C31018), the Project of Zhejiang Department of Education (Key Program, no. yb08110), and the Project of Zhejiang Department of Science and Technology (Key Program, 
no. 2013), for their financial support. Without their support, this work would not have been possible.

\section{References}

[1] K. Marković and M. Franulović, "Contact stresses in gear teeth due to tip relief profile modification," Engineering Review, vol. 31, no. 1, pp. 19-26, 2011.

[2] G. Zhang, P. Li, Y. Zou, and B. Wang, "Study of modification coefficient for less-teeth gear transmission," Applied Mechanics and Materials, vol. 26-28, pp. 483-488, 2010.

[3] G. Liu and R. G. Parker, "Dynamic modeling and analysis of tooth profile modification for multimesh gear vibration," Journal of Mechanical Design, Transactions of the ASME, vol. 130, no. 12, Article ID 121402, 13 pages, 2008.

[4] D. Yang, H. Y. Cui, X. J. Tian, Q. Zhang, and P. Xu, "Research on tooth modification of spur bevel gear," The Open Mechanical Engineering Journal, vol. 5, no. 1, pp. 68-77, 2011.

[5] Y. Hong-Liu, Y. Jin-Hua, H. Xin, and S. Ping, "Study on teeth profile modification of cycloid reducer based on non-Hertz elastic contact analysis," Mechanics Research Communications, vol. 48, pp. 87-92, 2013.

[6] J. I. Pedrero and M. Artés, "Approximate equation for the addendum modification factors for tooth gears with balanced specific sliding," Mechanism and Machine Theory, vol. 31, no. 7, pp. 925-935, 1996.

[7] S. Barone, L. Borgianni, and P. Forte, "Evaluation of the effect of misalignment and profile modification in face gear drive by a finite element meshing simulation," Journal of Mechanical Design-Transactions of the ASME, vol. 126, no. 5, pp. 916-924, 2004.

[8] F. L. Litvin, D. Vecchiato, E. Gurovich et al., "Computerized developments in design, generation, simulation of meshing, and stress analysis of gear drives," Meccanica, vol. 40, no. 3, pp. 291323, 2005.

[9] S. Baglioni, F. Cianetti, and L. Landi, "Influence of the addendum modification on spur gear efficiency," Mechanism and Machine Theory, vol. 49, pp. 216-233, 2012.

[10] V. V. Simon, "Influence of tooth modifications on tooth contact in face-hobbed spiral bevel gears," Mechanism and Machine Theory, vol. 46, no. 12, pp. 1980-1998, 2011.

[11] S. Li, "Finite element analyses for contact strength and bending strength of a pair of spur gears with machining errors, assembly errors and tooth modifications," Mechanism and Machine Theory, vol. 42, no. 1, pp. 88-114, 2007.

[12] Y. Wang, "Optimized tooth profile based on identified gear dynamic model," Mechanism and Machine Theory, vol. 42, no. 8, pp. 1058-1068, 2007.

[13] C. Zanzi and J. I. Pedrero, "Application of modified geometry of face gear drive," Computer Methods in Applied Mechanics and Engineering, vol. 194, no. 27-29, pp. 3047-3066, 2005. 

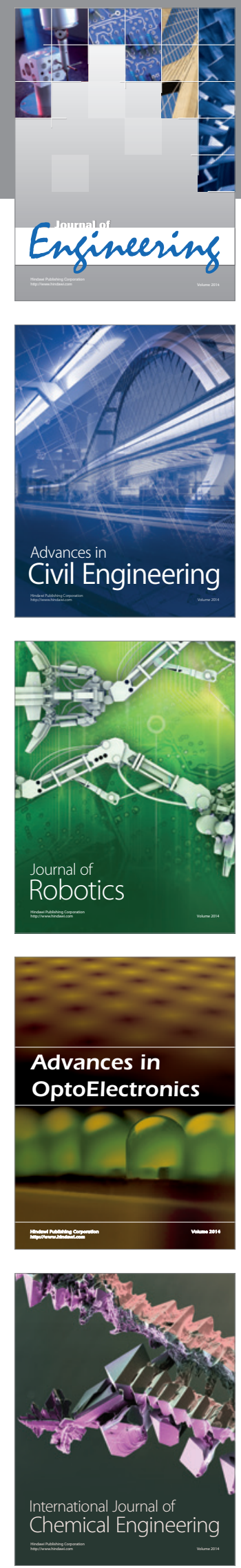

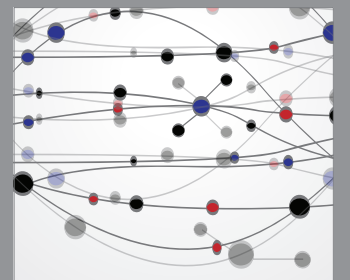

The Scientific World Journal
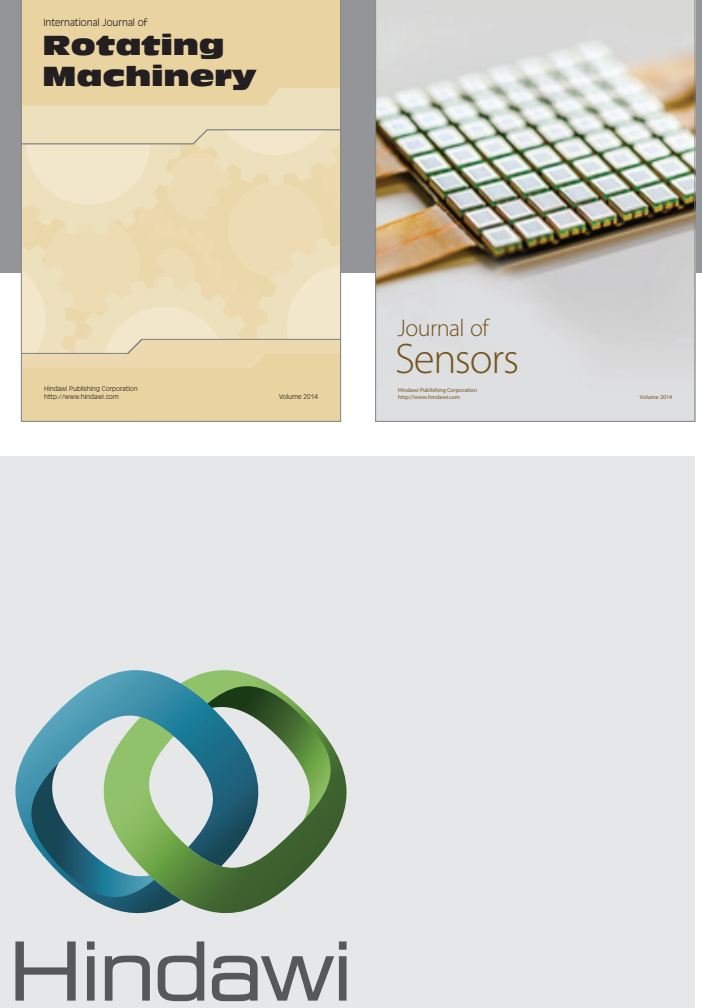

Submit your manuscripts at http://www.hindawi.com
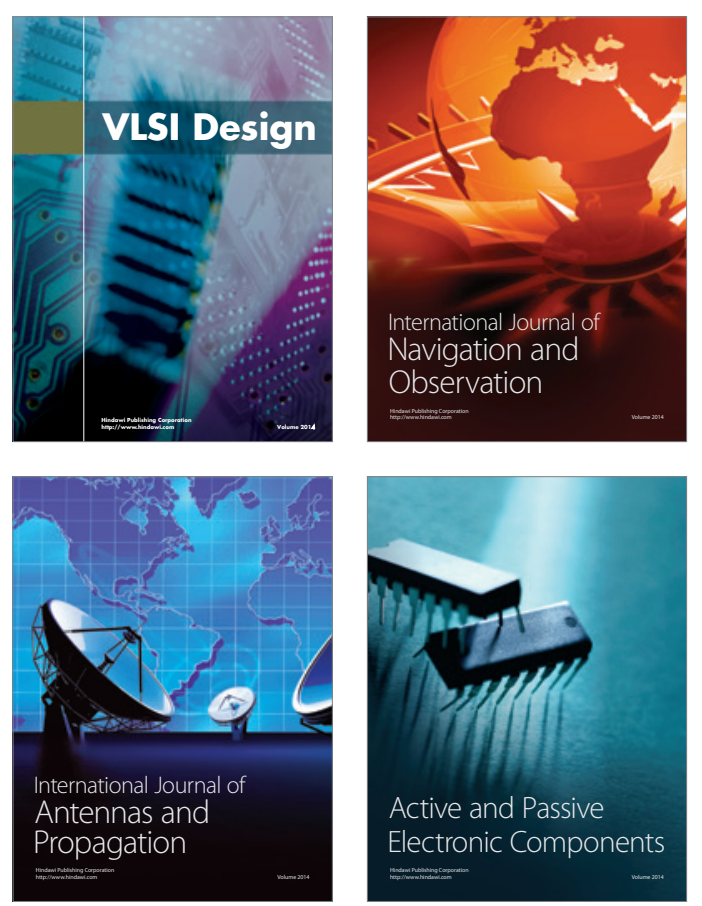
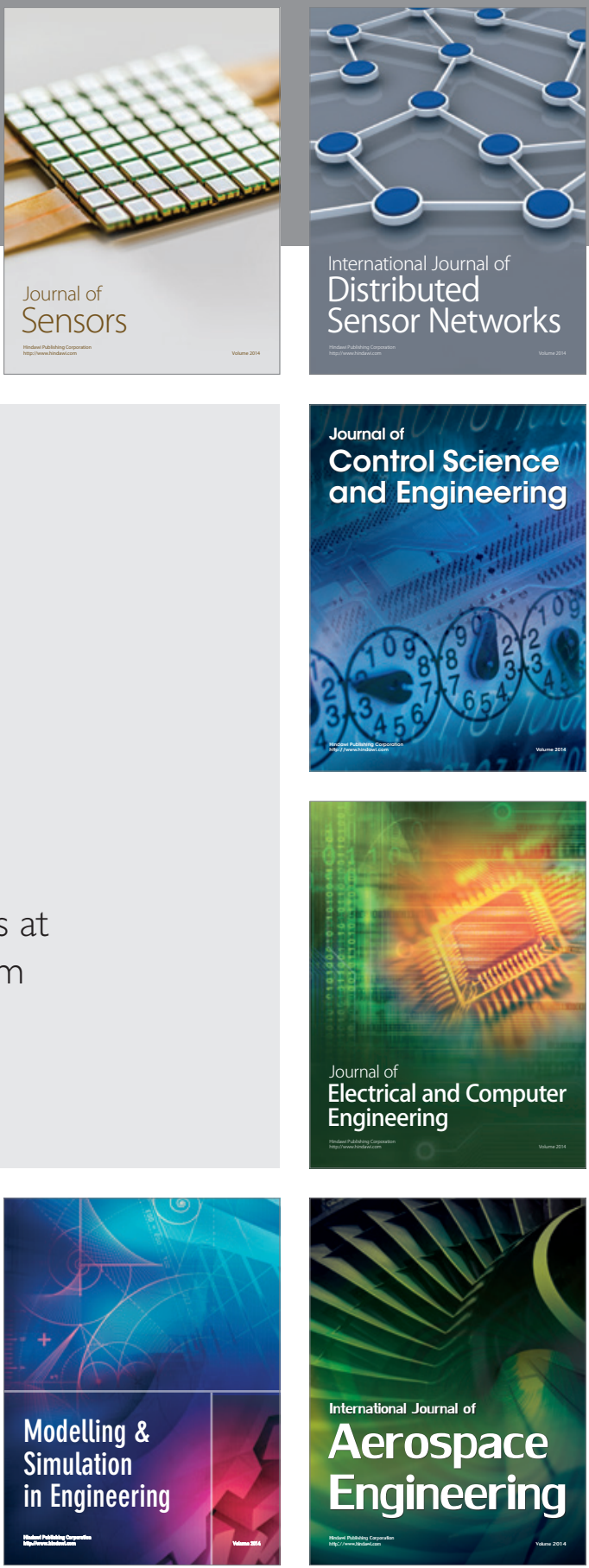

Journal of

Control Science

and Engineering
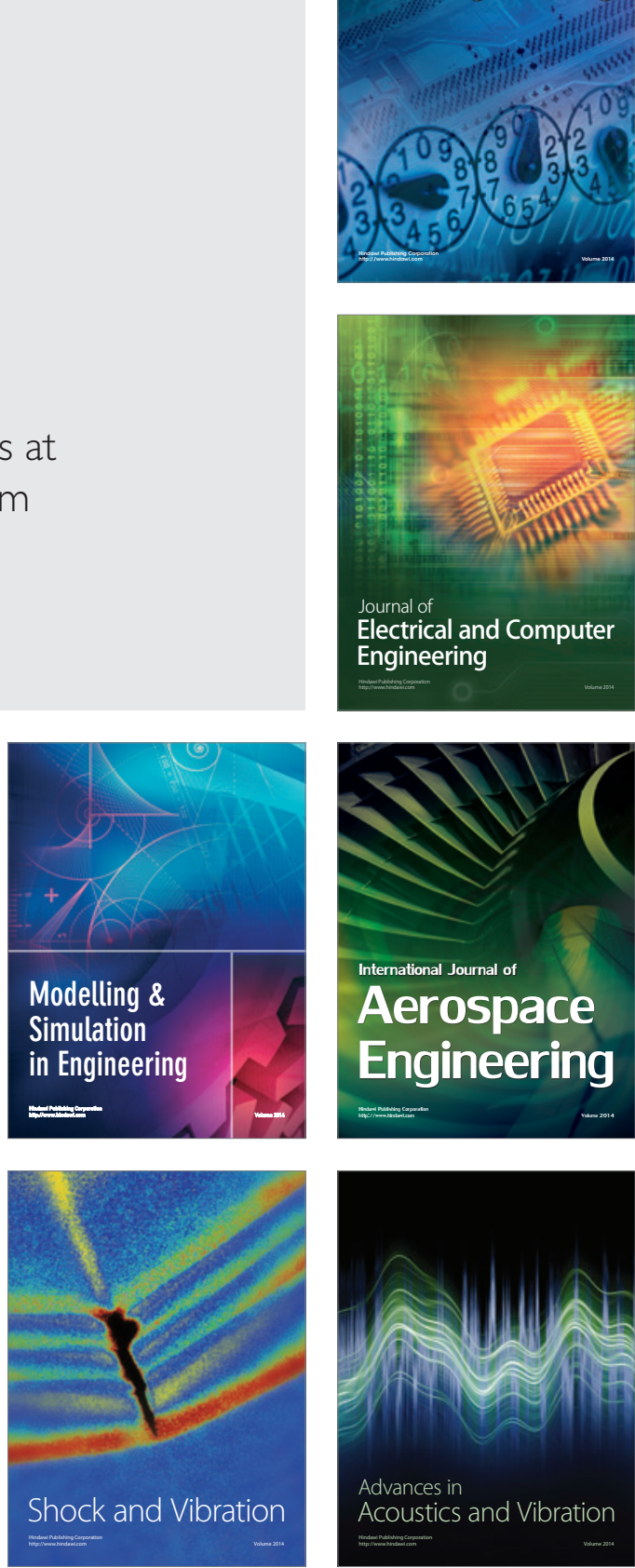